\title{
The Impact of Vibration Exercises on Shoulder Muscle Thickness
}

\author{
Jin-Gyu Jeong ${ }^{1}$, Jae-Cheol Park ${ }^{2}$
}

'Department of Physical Therapy, Chunnam Techno University, Jeollanam-do; ${ }^{2}$ Department of Physical Therapy, Graduate School, Nambu University, Gwangju, Korea

Purpose: The objective of this study was to examine the effect of vibration exercises generated from an $\mathrm{XCO}{ }^{\circledR}$ trainer on supraspinatus, infraspinatus, teres minor, and deltoid muscle thickness.

Methods: Thirty subjects were evenly divided into two groups. Muscle thickness was measured by a sonogram prior to the study, and at three and six weeks after the intervention. Changes in muscle thickness were analyzed using a repeated measure analysis of variance (ANOVA). The significance level for the statistical test was set at $\alpha=0.05$.

Results: A statistically significant differences in timing, interactions between timing and the groups, and between-group changes were demonstrated for supraspinatus muscle thickness $(p<0.05)$. A similar finding was reported for infraspinatus, teres minor, and deltoid muscles with regard to the interactions between timing and the groups $(p<0.05)$, although the between-group change did not reach statistical significance $(p>0.05)$.

Conclusion: Significant changes were observed in the thickness of the supraspinatus, infraspinatus, teres minor, and deltoid muscles, owing to the use of vibration exercises generated from an $\mathrm{XCO}^{\circledR}$ trainer. These findings can be used as a foundation for future studies on rehabilitation training.

Keywords: XCO, Thickness, Ultrasosnograph, Vibration

\section{서 론}

오목위팔관절은 운동 범위가 가장 넓은 관절이며, 위팔뼈 머리보다 어깨뼈의 관절 오목이 얕아 구조적으로 불안정하여 인체의 관절 중 탈구 가능성이 가장 큰 관절이다. 구조적으로 불안정한 오목위팔관 절의 움직임 증가와 탈구 및 불안정성을 방지하기 위해 돌림근띠, 위 팔두갈래근, 어깨세모근이 동적 안정성을 제공하여 2 안정성과 원활 한 움직임을 가능케 한다. 관절의 안정성을 제공하는 이들 근육의 약 화 또는 손상은 안정성을 유지하는 데 악영향을 미칠 뿐만 아니라 어 깨관절의 능동 운동 범위를 감소하게 하여 ${ }^{3}$ 기능적 움직임을 제한하 게 한다. ${ }^{4}$ 이러한 결과는 다양한 일상생활동작의 제약과 이차적 근뼈 대계 질환을 유발하며 회복되기까지 많은 시간과 비용이 투자된다. 그러므로 오목위팔관절의 능동 운동 범위와 근력, 지구력 등이 필요 하며 ${ }^{5}$ 이러한 능력은 어깨의 원활한 기능을 위한 필수적인 요소로 자 리잡고 있다.

오목위팔관절의 안정성과 운동 수행력을 증가시키는 방법으로 테
이핑요법, 슬링 78 , 클라이밍 운동 ${ }^{9}$, 어깨 안정화 운동 ${ }^{10}$ 방법 등이 있으 며 또 다른 방법으로 진동을 이용한 방법이 있다. 진동은 운동 도구 에 따라 수동과 능동 진동 자극으로 나뉜다. 수동 진동은 전신 진동 기구로 동심성 수축(concentric contraction)과 편심성 수축(eccentric contraction)을 주기적으로 반복하며" 근활성도를 증가시키고, 능동 진동은 대상자가 도구를 조작하여 발생하는 진동 자극으로 속도와 진폭을 스스로 조절하여 어깨 안정성을 증진하는 도구이다. ${ }^{12}$ 대표적 으로 바디 블레이드(body blade)가 있으며 $\mathrm{Kim}^{13}$ 은 바디 블레이드를 이용한 진동 운동에서 어깨 근육인 가시아래근과 앞톱니근의 근활 성도가 증가하였다고 하여 능동 진동의 긍정적인 부분을 확인하였 다. 진동이 발생할 때 주어지는 동적 수축은 근육 강화에 도움이 되 고 $^{14}$ 건강한 성인의 근육 강화를 위해서도 진동은 이용되고 있다. ${ }^{15}$ 하 지만 수동 진동의 단점으로 지속적인 진동에너지의 저장의 어려움 과 ${ }^{16}$ 고가의 장비로 인한 접근성이 어려워 본 연구에서는 바디 블레 이드와 비슷한 능동 진동을 유발하는 익스코( $\mathrm{XCO}^{\circledR}, \mathrm{eXtreme} \mathrm{COre}$ training) 도구를 이용하였다. 
익스코는 위, 아래, 좌, 우 다방향으로 흔듦에 따라 반응 충격(reaction attack)이 관절 주변 조직과 근육으로 전달되고 그로 인해 근육의 주동근과 길항근의 동시 활성화가 유발되어 근력을 강화하는 데 있 어 효과적이다. ${ }^{17}$ 익스코 도구를 이용한 선행연구로는 60 대 노인 23명 을 대상으로 노르딕 걷기와 익스코 도구를 이용한 걷기 훈련 비교 연 구에서 고령자의 심장박동수, 산소섭취량 $(\mathrm{VO} 2)$ 과 젓산 농도가 변화 하여 지구력 훈련 프로그램으로 적합하다고 하였고 ${ }^{18}$ 또다른 연구에 서는 익스코를 이용한 바깥돌림과 굽힘 훈련을 한 군에서 다른 군에 비해 앞톱니근의 근활성도가 증가하였다고 보고하였다. ${ }^{19} \mathrm{Cho}^{20}$ 는 익 스코 몸통 안정화 훈련이 배속빗근의 근두께 변화를 발생시켰다고 보고하였고, 만성요통환자에게 익스코를 적용한 연구에서도 익스코 운동군이 다른 군보다 몸통 근육의 근활성도가 증가하였다고 보고 하여 ${ }^{21}$ 그 효과를 검증하였다.

선행연구들을 통해 익스코를 이용한 운동의 긍정적인 효과들이 보고 되고 있지만, 익스코 도구를 이용하여 어깨 안정화에 기여하는 가시위근, 가시아래근, 작은원근, 어깨세모근의 두께 변화를 초음파 를 이용하여 구조적 변화를 확인한 연구는 없는 실정이다. 그러므로 본 연구는 익스코 도구를 이용하여 어깨 안정성에 관여하는 어깨 근 육의 두께 변화에 미치는 영향을 연구하고자 하며, 따라서 본 연구는 익스코 도구를 이용한 어깨 안정화 운동 적용 후 초음파 영상 분석 방법을 이용하여 어깨 근육의 구조적 변화를 확인하고자 하며 어깨 관련 기초자료와 임상에서 재활 프로그램으로 활용 가능성을 제시 하고자 한다.

\section{연구 방법}

\section{1. 연구대상}

본 연구는 전남 소재 J대학에 재학 중인 20대 30명을 대상으로 근뼈대 계 질환이 없는 자로 선정하여 군에 대한 정보를 설명하지 않고 익스 코 운동군 15 명, 탄력밴드 운동군 15 명을 무작위로 배정하여 연구자 임의 배정방식에 의하여 무작위로 분류를 하였고 단일맹검법(singleblind test)에 의한 대상자 선정을 하였다. 실험 전 연구 목적과 연구 방 법을 설명하고 자발적인 연구 참여 의사를 밝힌 자를 대상으로 연구 동의서를 작성하여 연구를 진행하였다. 실험 전 동질성 검정 결과 일반

Table 1. General characteristics of subjects

\begin{tabular}{lccc}
\hline & XCEG $(\mathrm{N}=15)$ & SB EG $(\mathrm{N}=15)$ & $\mathrm{p}$ \\
\hline Age (year) & $21.86 \pm 2.50$ & $22.26 \pm 1.33$ & 0.067 \\
Height $(\mathrm{cm})$ & $166.46 \pm 7.62$ & $168.80 \pm 5.89$ & 0.791 \\
Weight $(\mathrm{kg})$ & $64.13 \pm 10.78$ & $58.64 \pm 9.46$ & 0.309 \\
BMI $\left(\mathrm{kg} / \mathrm{m}^{2}\right)$ & $23.00 \pm 2.42$ & $20.48 \pm 2.34$ & 0.825 \\
\hline
\end{tabular}

XC EG: XCO exercise, SB EG: Thera band exercise, BMI: body mass index.
적 특성인 연령, 몸무게, 신장, 체질량 지수에서 유의한 차이가 없어 같 은 집단임을 확인하였고 일반적 특성은 다음과 같다(Table 1).

\section{2. 실험방법}

오목위팔관절 주변의 근육 강화를 위해 익스코 운동군(XCO exercise $\mathrm{XCEG)}$ 은 중간(medium) 크기인 익스코를 이용하여 훈련하였고 훈련 제품의 지름과 중량은 $42.5 \times 5 \mathrm{~cm} / 600 \mathrm{~g}$ 이다. 운동 자세로는 세 가지 자세에서 실시하였다. 첫 번째 자세는 바로 선 자세에서 어깨관절을 $90^{\circ}$ 벌림 하여 머리에서 넙다리 부위까지 위아래로 흔들어 벌림과 폄 운동을 실시하였고, 두 번째 자세로는 어깨관절 $90^{\circ}$ 굽힘 하여 머리에 서 배꼽 부위까지 위아래로 흔들어 굽힘과 폄 운동을 하였다. 세 번째 자세로는 어깨관절 $90^{\circ}$ 굽힘, 팔꿈치관절 $90^{\circ}$ 굽힘 하여 앞뒤로 흔들 며 $90^{\circ}$ 의 각도가 넘지 않은 범위에서 어깨관절의 안쪽 및 가쪽 돌림 운동을 최대한 빠른 속도로 실시하였고 속도가 떨어질 때 언어로 피 드백을 주었다. 탄력밴드 운동군(Thera band exercise SBEG)은 탄력밴 드를 이용하여 세 가지 자세 운동을 하였다. 첫 번째 자세는 양발을 탄 력밴드를 밟아 고정한 상태에서 어깨너비로 벌림 상태로 선 후 양손 을 탄력밴드를 잡고 어깨 관절 $90^{\circ}$ 벌림 운동을 하였다. 두 번째 자세 는 첫 번째 자세와 같은 자세에서 방향을 바꾸어 굽힘 운동을 하였다. 세 번째 자세는 탄력밴드를 기둥에 고정하고, 옆으로서 위팔을 몸통 에 붙인 후 팔꿈치관절을 $90^{\circ}$ 도 굽힘을 하여 가쪽 돌림 운동을 하였 다. 그룹별 운동은 일일 본 운동에 앞서 준비 운동 5 분, 본 운동 30 분, 마무리 운동 5 분으로 총 40 분 중재 주 3 회 총 6 주간 실시하였다.

\section{1) 측정도구}

돌림근띠와 어깨세모근의 근두께 측정을 위해 초음파영상장치를 (Mylabone Esaite, Italy)를 이용하였다. 주파수 변조 범위는 $10 \mathrm{MHz}$ 로 설정하였고 초음파 변환기는 $7.5 \mathrm{MHz}$ 의 선형탐촉자(linear transduc$\mathrm{er}, \mathrm{SL} 3323)$ 를 이용하였으며 민감도는 G60과 동적 범위 C4로 고정하 여 사용하였다. 근두께 측정 자세로는 상의 탈의 한 후 근수축이 발 생하지 않게 팔걸이 의자에 팔을 올려놓고 편하게 앉은 자세를 취한 뒤 어깨뼈의 어깨뼈가시에서 위쪽 $2.5 \mathrm{~cm}$ 지점과 안쪽모서리 $2.5 \mathrm{~cm}$ 떨어진 지점에서 가시위근을 측정하였고, 가시아래근은 어깨뼈가시 아랫부분으로 $5 \mathrm{~cm}$ 떨어진 지점과 어깨뼈 내측 면 $2.5 \mathrm{~cm}$ 에서 측정하 였다. ${ }^{22}$ 어깨세모근의 중간섬유를 측정하기 위해 시상면(sagittal plane) 에서 어깨뼈봉우리를 확인한 후 팔 먼쪽부위로 $10 \mathrm{~cm}$ 이동 후 측정 하였고, 작은원근은 엎드려 누운 자세에서 어깨관절 $90^{\circ}$ 벌림을 하였 고 아래팔은 테이블 밖으로 늘어뜨린 후 어깨뼈의 가쪽모서리 가운 데 부위에서 측정하였다. 변환기를 이용하여 측정된 이미지를 초음 파에 내장된 캘리퍼를 이용하여 근막이 포함되지 않게 두께를 측정 하였고, 측정 시 시기별 측정 부위를 최소화하기 위해 수술용 펜으로 
표시한 후 시행하였으며 검사자 간 차이를 줄이기 위해 어깨관절의 해부학적 이해와 초음파 검사기에 숙달된 물리치료사 1 인을 정하여 오른쪽 어깨 근육을 측정하였다. 총 3 회 반복 측정한 후 평균값을 근 두께로 이용하였다.

\section{2) 통계 방법}

수집된 자료는 SPSS 18.0 통계 프로그램을 이용하여 평균과 표준편 차를 산출하였고, 두 그룹의 훈련 전, 3 주 후, 6 주 후의 측정 변인에 대
한 차이를 알아보고자 반복측정분산분석(repeated measure ANOVA) 을 이용하였고 사후분석으로 Schesse 검정을 하였으며 통계학적 유 의성을 검정하기 위해 유의수준은 0.05 로 하였다.

\section{결 과}

\section{1. 가시위근의 근두께 변화}

각 군의 가시위근의 두께 변화에 대한 반복측정분산분석 결과 시기

Table 2. Comparison of shoulder muscle thickness

$(\mathrm{mm})$

\begin{tabular}{|c|c|c|c|c|c|c|c|}
\hline & & \multirow{2}{*}{ Pre } & \multirow{2}{*}{3 weeks } & \multirow{2}{*}{6 weeks } & \multicolumn{3}{|c|}{$\mathrm{F}$} \\
\hline & & & & & Time & Group & Time $\times$ Group \\
\hline \multirow[t]{2}{*}{ SS } & XCEG & $14.13 \pm 2.02$ & $15.76 \pm 2.16$ & $17.13 \pm 2.09$ & $200.352^{*}$ & $4.284^{*}$ & $146.770^{*}$ \\
\hline & SBEG & $14.09 \pm 1.82$ & $14.21 \pm 1.76$ & $14.33 \pm 1.81$ & & & \\
\hline \multirow[t]{2}{*}{ IS } & XCEG & $13.05 \pm 1.96$ & $14.57 \pm 1.83$ & $15.97 \pm 1.74$ & $191.781^{*}$ & 3.107 & $44.902^{*}$ \\
\hline & SBEG & $12.89 \pm 1.87$ & $13.35 \pm 1.70$ & $13.90 \pm 1.73$ & & & \\
\hline \multirow[t]{2}{*}{ TM } & XCEG & $9.35 \pm 2.07$ & $10.16 \pm 1.79$ & $11.22 \pm 1.99$ & $137.117^{*}$ & 1.227 & $27.175^{*}$ \\
\hline & SBEG & $9.19 \pm 1.77$ & $9.42 \pm 1.72$ & $9.90 \pm 1.69$ & & & \\
\hline \multirow[t]{2}{*}{ DEL } & XCEG & $10.17 \pm 1.74$ & $11.66 \pm 1.83$ & $12.91 \pm 1.77$ & $183.284^{*}$ & 2.277 & $96.038^{*}$ \\
\hline & SBEG & $10.29 \pm 2.23$ & $10.40 \pm 2.23$ & $10.74 \pm 2.25$ & & & \\
\hline
\end{tabular}

SS: supraspinatus thickness, IS: infraspinatus thickness, TM: teres minor thickness, DEL: deltoid thickness, XCEG: XCO exercise, SBEG: Thera band exercise. ${ }^{*} p<0.05$.

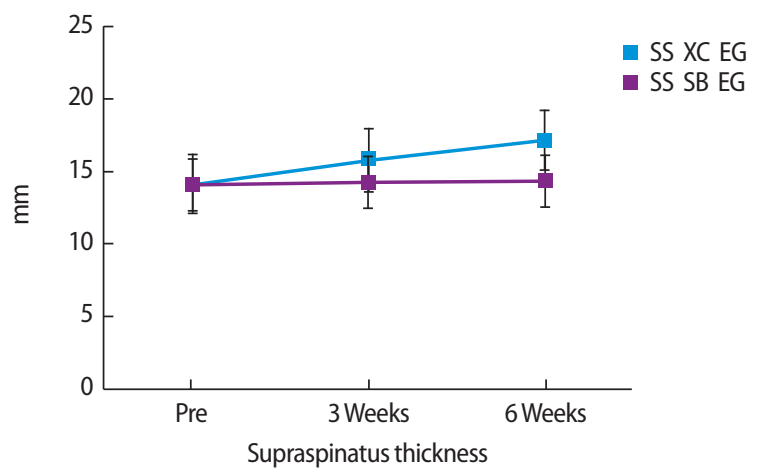

Figure 1. Comparison of supraspinatus thickness.

SS: supraspinatus thickness, XCEG: XCO exercise, SBEG: Thera band exercise.

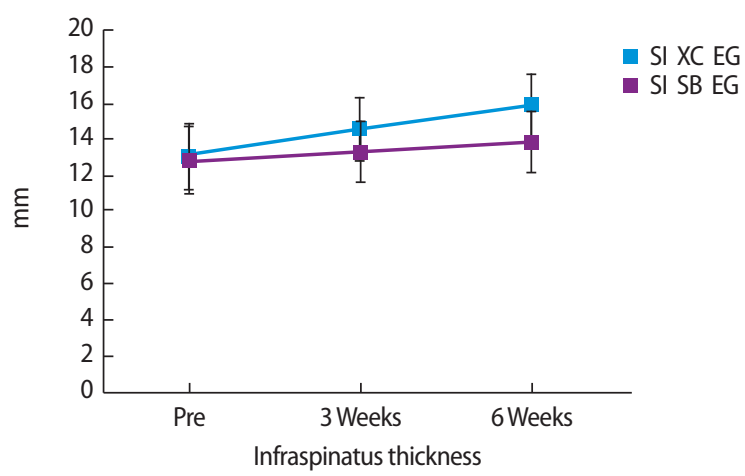

Figure 2. Comparison of infraspinatus thickness.

IS: infraspinatus thickness, XCEG: XCO exercise, SBEG: Thera band exercise.

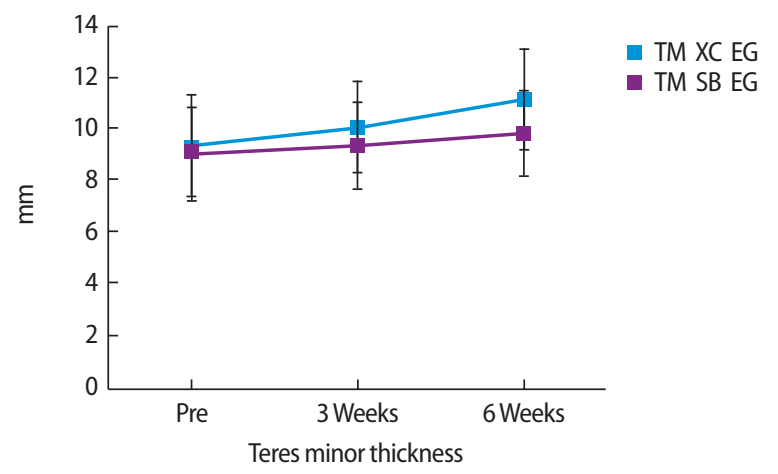

Figure 3. Comparison of teres minor thickness.

TM: teres minor thickness, XCEG: XCO exercise, SBEG: Thera band exercise.

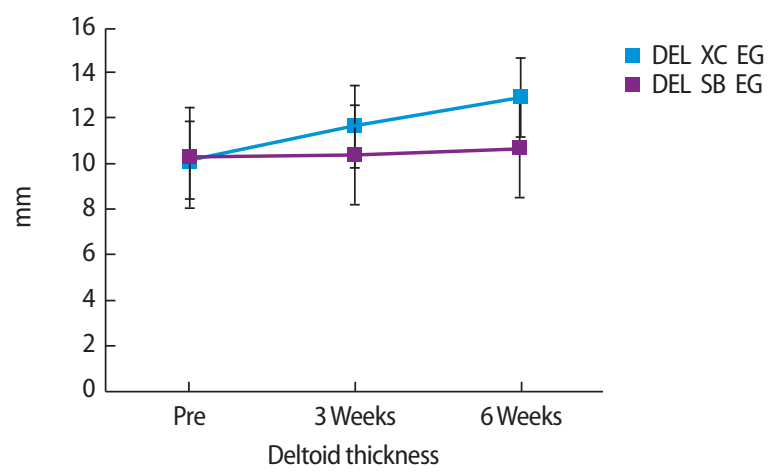

Figure 4. Comparison of deltoid thickness.

DEL: deltoid thickness, XCEG: XCO exercise, SBEG: Thera band exercise. 
별, 시기와 집단 간, 군 간 변화에서 유의한 차이가 있었다 $(\mathrm{p}<0.05)$ (Table 2)(Figure 1).

\section{2. 가시아래근의 근두께 변화}

각 군의 가시아래근의 두께 변화에 대한 반복측정분산분석 결과 시 기별, 시기와 집단 간 변화에서 유의한 차이가 있었고 $(\mathrm{p}<0.05)$, 군 간 변화에서는 유의한 차이가 없었다(p>0.05)(Table 2)(Figure 2).

\section{3. 작은원근의 근두께 변화}

각 군의 작은원근의 두께 변화에 대한 반복측정분산분석 결과 시기 별, 시기와 집단 간 변화에서 유의한 차이가 있었고 $(\mathrm{p}<0.05)$, 군 간 변 화에서는 유의한 차이가 없었다( $p>0.05)($ Table 2)(Figure 3).

\section{4. 어깨세모근의 근두께 변화}

각 군의 어깨세모근의 두께 변화에 대한 반복측정분산분석 결과 시 기별, 시기와 집단 간 변화에서 유의한 차이가 있었고 $(\mathrm{p}<0.05)$, 군 간 변화에서는 유의한 차이가 없었다(p>0.05)(Table 2)(Figure 4).

\section{고 찰}

본 연구는 20 대 건강한 성인 30 명을 대상으로 익스코 운동군과 탄력 밴드 운동군으로 나누어 총 6 주간 운동을 한 후 실험 전, 3 주 후, 6 주 후로 시기를 나누어 가시위근, 가시아래근, 작은원근, 어깨세모근의 근두께를 초음파를 이용하여 분석하였다. 본 연구에 이용된 초음파 는 심부 구조 확인과 측정에 필요한 장비이며 ${ }^{23}$ 초음파 신뢰도 연구 에서 신뢰도가 높은 장비로 근두께 측정에 자주 이용되고 있다. ${ }^{24}$

진동은 근육 강화에 도움이 되며 ${ }^{4}$ 근육 강화를 위해서 진동을 유 발하는 여러 장비가 이용된다. 그 중 전신 진동(whole body vibration) 기구는 수동자극으로 근육에 적용되면 근방추의 활성화를 유발하 여 근육을 강화한다. ${ }^{25}$ 반면에 익스코와 같은 운동 도구는 능동자극 으로 다방향으로 흔들 때 마지막 범위에서 발생하는 반응 충격으로 근육을 강화한다. ${ }^{17}$ Page 등 ${ }^{26}$ 은 익스코와 비슷한 효과를 발생시키는 세라밴드 플랙스바(Thera-band flexbar)를 이용하여 위팔근의 근활성 도 결과를 정량화하였고 능동 진동 자극을 유발하는 도구는 상체의 $1 / 4$ 근육을 활성화시켜 근육 강화에 이득이 있다고 하였다. 이에 본 연구는 능동자극에 속하는 익스코를 이용한 운동을 적용 후에 어깨 안정화 근육의 두께 변화에 미치는 영향을 확인하고자 하여 본 연구 를 시행하였다. 그 결과 가시위근의 근두께 변화는 시기별, 시기와 군 간 상호작용, 집단 간 변화에서 유의한 차이를 보였다 $(\mathrm{p}<0.05)$. 가시 아래근과 작은원근 어깨세모근의 근두께 변화는 시기별, 시기와 군 간 상호작용은 유의한 차이를 보였고 $(\mathrm{p}<0.05)$, 군 간 비교에서는 유의
한 차이가 발생하지 않았다 $(\mathrm{p}>0.05)$.

익스코 관련 선행연구를 살펴보면 Son는 익스코 도구를 이용하 여 만성요통환자 20 명을 대상으로 익스코 운동군과 허리 안정화운 동군으로 나누어 실시한 결과 배곧은근 배바깥빗근 배속빗근 척추 세움근의 근활성도 변화와 배 근력 변화에서 상호작용에서 유의한 차이가 발생했다고 보고하였다. 본 연구와 운동 방법과 측정 장비가 다르지만 본 연구와 유사한 결과가 발생하였고, 가시아래근과 작은 원근 어깨세모근의 군 간 비교에서 유의한 차이가 발생하지 않은 것 은 가면효과(masking effect)로 상호작용의 효과가 유의한 주효과를 가리는 효과로 인한 결과로 생각된다.27

초음파를 이용하여 몸통 근육의 구조적 변화를 살펴본 연구에서 $\mathrm{Cho}^{20}$ 는 22명을 대상으로 익스코 몸통 안정화 운동이 배바깥빗근을 제외한 배곧은근, 배속빗근, 배가로근, 뭇갈래근은 시기에 따른 차이 가 있었고 배속빗근은 상호작용에서 유의한 차이가 있었다고 보고 하였다. 또다른 연구에서는 Son ${ }^{28}$ 은 30 명을 이용하여 8 주간 익스코를 이용한 몸통 안정화 운동군과 전통적인 몸통 안정화운동군 간에 배 가로근의 근두께 차이가 없다고 보고하였다. 이러한 결과는 본 연구 와 차이가 있었고 운동 방법과 운동 효과에서 그 차이를 찾을 수 있 다. 선행연구는 넓은 지지면과 낮은 무게중심을 이용한 네발기기 자 세와 누운 자세로 익스코 운동을 시행하였고, 그 반면에 본 연구는 좁은 지지면과 높은 무게중심을 이용한 선 자세에서 진동운동을 실 시하여 더욱 많은 진동 자극이 발생하여 어깨 안정화 근육에 영향을 미치고 동시 수축을 일으킨 결과로 생각된다.29

진동 운동은 길항근인 긴장성 근육(tonic muscle)보다 위상성 근육 (phasic muscle)이 더 많이 활성화하며 어깨 근육을 증가시키는 능력을 갖추고 있다. ${ }^{30}$ 하지만 본 연구에서는 I형 타입과 II형 타입의 모든 근 육의 두께가 증가하였다. 이러한 결과는 운동 도구에서 그 차이를 찾 을수 있는데 $\mathrm{Cho}^{19}$ 는 수동운동으로 인해 발생하는 수동 진동은 약한 주파수로 인해 근지구력에 효과적이고 익스코와 같은 훈련 도구는 강하고 빠른 진동으로 인해 최대 근력을 유발하기에 적합하다고 하였 다. 수동 진동을 유발하는 전신 진동과 능동 진동을 유발하는 플랙스 바 같은 훈련은 마지막 범위에서 반응 충격이 없는 반면 능동 진동을 유발하는 익스코 훈련도구는 운동 전체범위에서 최대 근력을 또한 마지막 범위에서 추가적인 자극이 유발되어 어깨 안정화에 관여하는 I형 타입과 II형의 근육들 모두 증가하지 않았나 판단된다.

익스코와 비슷한 자극을 유발하는 도구로는 바디 블레이드가 있 다. 바디블레이드는 팔의 먼쪽 부위에서 몸쪽으로 진동을 전달하여 근육을 강화하는 운동으로 ${ }^{31}$ 운동 관점에서 봤을 때 익스코와 비슷 한 효과를 발생시킨다. Lister 등 32 은 바디블레이드에 의해 발생하는 능동 진동 자극은 팔과 어깨에 근수축을 유발한다 하였고, 탄력밴드 와 커프웨이트(Cuff weights), 바디블레이드로 군을 나누어 어깨 운동 
을 한 결과 바디블레이드군의 어깨관절 굽힘과 벌림 운동에서 어깨 근활성도가 높게 나타난다고 보고하였다. 바디블레이드군의 굽힘과 벌림 운동은 본 연구 운동 방법과 비슷한 방법으로 익스코 운동 자 세에서 어깨 굽힘과 벌림 동작을 시행하여 어깨 근육의 활성화가 더 욱 많이 활성화되어 이러한 결과가 발생한 것으로 생각된다. 또한 손 에 진동을 유발하는 운동은 운동 사슬 관점에서 닫힌 사슬운동 (closed kinetic chain exercises)의 효과를 가져오며 어깨 안정성을 증가 시키기 위해 고유수용성감각의 촉진이 발생한다. ${ }^{33}$ 고유수용성감각 증가는 어깨 안정화에 관여하는 근육과 관절의 협력 작용으로 근육 의 강화에 이득이 발생하고 어깨의 안정화에 효과적인 결과가 발생 한 것으로 생각된다. 본 연구를 종합해보면 익스코를 이용한 어깨 진 동 운동은 어깨 안정성에 관여하는 가시위근, 가시아래근, 작은원근, 어깨세모근의 두께 증가에 효과적으로 나타났다.

본 연구의 제한점은 특정 지역, 특정 연령대와 적은 대상자로 이용 하여 일반화하기에 어려움이 있고 초음파 측정기기로만 근두께 측정 을 하여 두께와 관련이 있는 근력이나 지구력 관련 변수에 대한 부분 을 확인하지 못한 점이 아쉬움으로 남는다. 하지만 익스코 어깨 안정 화 운동으로 인한 변화는 긍정적으로 생각된다. 차후 다양한 연령층 및 대상자, 충분한 운동 기간과 여러 측정 장비의 다변화를 통해 많 은 질적 연구가 필요할 것으로 생각된다.

\section{참고문헌}

1. Miller MD, Cooper DE, Warner JJ. Review of sports medicine and arthroscopy. Collingwood, Saunders Book Company, 2002.

2. Kisner C, Colby LA, Borstad J. Therapeutic exercise: foundations and techniques. Philadelphia, FA Davis, 2017.

3. Seo H, Lee K, Jung K et al. Reliability and validity of the Korean version of shoulder pain and disability index. J Spec Educ Rehabil Sci. 2012; 51(2):319-36.

4. Neumann DA. Kinesiology of the musculoskeletal system-e-book: Foundations for rehabilitation. Amsterdam, Elsevier Health Sciences, 2013.

5. Sokk J, Gapeyeva H, Ereline J et al. Shoulder muscle function in frozen shoulder syndrome patients following manipulation under anesthesia: A 6-month follow-up study. Orthop Traumatol Surg Res. 2013;99(6): 699-705.

6. Lim HW. Does Kinesio taping improve vertical jumping performance? J Kor Phys Ther. 2016;28(5):269-73.

7. Choi EY, Choi H. The effect of exercise using grasping on shoulder muscle activity and muscle thickness of patients with rotator cuff repair. J Kor Phys Ther. 2016;28(1):52-8.

8. Kim JW, Kim YN. Effect of sling exercise on muscle activity and pain in patients with rotator cuff repair. J Kor Phys Ther. 2017;29(2):45-9.

9. Kim EJ, Kim SH. A comparison of shoulder stabilizer muscle activities of therapeutic climbing and isometric exercise in patients with shoulder impingement syndrome. J Kor Phys Ther. 2016;28(2):88-94.
10. Yang DJ, Uhm YH, Kim JH. The biofeedback scapular stabilization exercise in stroke patients effect of muscle activity and function of the upper extremity. J Kor Phys Ther. 2015;27(5):325-31.

11. Cardinale M, Wakeling J. Whole body vibration exercise: Are vibrations good for you? Br J Sports Med. 2005;39(9):585-9.

12. Buteau JL, Eriksrud O, Hasson SM. Rehabilitation of a glenohumeral instability utilizing the body blade. Physiother Theory Pract. 2007;23(6):33349.

13. Kim EK. The Effect of bodyblade training on body alignment of neck and shoulder, muscle activity, stability, and foot pressure at forward head postur. Daegu University. Dissertation of Doctorate Degree. 2014.

14. Cardinale M, Rittweger J. Vibration exercise makes your muscles and bones stronger: Fact or fiction? J Br Menopause Soc. 2006;12(1):12-8.

15. Cohen LG, Starr A. Vibration and muscle contraction affect somatosensory evoked potentials. Neurology. 1985;35(5):691-8.

16. Derrick TR, Dereu D, Mclean SP. Impacts and kinematic adjustments during an exhaustive run. Med Sci Sports Exerc. 2002;34(6):998-1002.

17. Müller-Wohlfahrt HW, Schmidtlein O. Besser trainieren!: So lernen sie von den neuen erfolgsstrategien der profis. Munchen, Goldmann, 2007.

18. Morat T, Krueger J, Gaedtke A et al. Effects of 12 weeks of nordic walking and XCO walking training on the endurance capacity of older adults. Eur Rev Aging Phys Act. 2017;14(1):16.

19. Maenhout A, Benzoor M, Werin M et al. Scapular muscle activity in a variety of plyometric exercises. J Electromyogr Kinesiol. 2016;27:39-45.

20. Cho W, Park C, Lim H. The effect of trunk strengthening exercise using oscillation on trunk muscle thickness and balance. J Korean Soc Phys Med. 2017;12(2):91-101.

21. Son SA. The effects of XCO and lumbar stabilization exercise on trunk muscle activity, back strength, and pain in the patients with chronic low back pain. Nambu University. Dissertation of Master's Degree. 2015.

22. Juul-Kristensen B, Bojsen-Møller F, Holst E et al. Comparison of muscle sizes and moment arms of two rotator cuff muscles measured by ultrasonography and magnetic resonance imaging. Eur J Ultrasound. 2000; 11(3):161-73.

23. Rankin G, Stokes M, Newham D. Size and shape of the posterior neck muscles measured by ultrasound imaging: normal values in males and females of different ages. Man Ther. 2005;10(2):108-15.

24. Lee JA, Kim SY. Reliability of ultrasonography for the longus colli in asymptomatic subjects. J Korean Soc Phys Ther. 2011;23(4):59-66.

25. Bogaerts A, Verschueren S, Delecluse C et al. Effects of whole body vibration training on postural control in older individuals: A 1 year randomized controlled trial. Gait Posture. 2007;26(2):309-16.

26. Page P, Ross O, Rogers M et al. Muscle activity of the upper extremity during oscillation exercise using the Thera-band flexbar. Hand Prints. 2004;21(5):7.

27. Sung N. Analysis and experiment of repetitive measurement. Paju, Free Academy, 1997:113.

28. Son PY. The effect of XCO exercise and lumbar stabilization exercise on thickness of lumbar muscle and pain disability index with chronic low back pain patients. Nambu University. Dissertation of Master’s Degree. 2015.

29. Cools AM, Dewitte V, Lanszweert F et al. Rehabilitation of scapular muscle balance: which exercises to prescribe? Am J Sports Med. 2007; 35(10):1744-51. 
30. Page P, Frank C, Lardner R. Assessment and treatment of muscle imbalance: the janda approach. Champaign, Human Kinetics, 2010.

31. Prentice WE, Voight ML. Techniques in musculoskeletal rehabilitation. NewYork, McGraw-Hill Medical, 2001.

32. Lister JL, Del Rossi G, Ma F et al. Scapular stabilizer activity during Bodyblade, cuff weights, and Thera-band use. J Sport Rehabil. 2007;
16(1):50-67.

33. Tucker WS, Armstrong CW, Gribble PA et al. Scapular muscle activity in overhead athletes with symptoms of secondary shoulder impingement during closed chain exercises. Arch Phys Med Rehabil. 2010;91(4):5506. 